\title{
Global Sensitivity Analysis for Radionuclides Transport in a Generic Clay Repository
}

\author{
DinARA ERMAKOVA ${ }^{1,2^{*}}$, HARUKO WAINWRIGHT ${ }^{1,2}$, \\ LIANGE ZHENG ${ }^{2}$ \\ ${ }^{1}$ University of California, Berkeley, CA 94709,USA \\ (*ermakova@berkeley.edu) \\ ${ }^{2}$ Lawrence Berkeley National Lab., Berkeley, CA 94720,USA
}

\section{Objective}

The long-term integrity of bentonite buffer is of significant interest in the performance assessment of geological nuclear waste disposal. This study aims at understanding how the interaction between host rock and bentonite affects chemical properties of bentonite buffer which will subsequently affect the transport of radionuclides. Using coupled thermal-hydrological-chemical (THC) models for migration of $\mathrm{U}(\mathrm{VI})$ in a generic repository, we performed global sensitivity analysis to identify the influence of each parameter on the temporal evolution of spatially averaged distribution coefficient, $\mathrm{Kd}$, for the entire buffer, which can be used in a repository-scale performance assessment (PA) model[1].

\section{Approach and Results}

We used TOUGHREACT software to model coupled THC processes in a generic clay repository with bentonite buffer [2,3]. U(VI) is released from canister via schoepite dissolution that is assumed to occur after 1000 years and migrates through the buffer affected by two-site protolysis non-electrostatic surface complexation and cation exchange [4].

Global sensitivity analysis was performed based on the Morris method by varying chemical parameters, including $\mathrm{pH}$, mineral volume fractions and ion concentrations. Results show that smectite, illite site densities, volume fractios of illite calcite, and $\mathrm{Ca}^{2+}$ concentration play a significant role in $\mathrm{U}(\mathrm{VI})$ transport since roughly $80 \%$ of adsorbed U(VI) is on smectite and $\mathrm{Ca}^{2+}$ affects the aqueous complexation with $\mathrm{U}(\mathrm{VI})$. This work demonstrates complex process models that can be transferred to the PA model. It also provides information needed to proceed with development of reducesorder model, which has a potential to optimize repository designs, site characterization and performance confirmation.

[1] C.Bethke et al.(2010).Ground Water, 38, 435-443.

[2] $\mathrm{T}$. $\mathrm{Xu}$ et al. (2014) TOUGHREACT V3. 0-OMP reference manual.

[3] L. Zheng et al. (2017) Eng. Geol., 230, 118-129.

[4] M. Bradbury et al. (2011) Applied Clayence, 52, 2733. 